SHORT REPORT

\title{
Gamma-S crystallin gene (CRYGS) mutation causes dominant progressive cortical cataract in humans
}

\author{
H Sun*, Z Ma*, Y Li, B Liu, Z Li, X Ding, Y Gao, W Ma, X Tang, X Li, Y Shen
}

J Med Genet 2005;42:706-710. doi: 10.1136/jimg.2004.028274

Background: Congenital or childhood cataract is clinically and genetically a highly heterogeneous lens disorder in children. Autosomal dominant inheritance is most common. Objective: To report the identification of a mutation in the human CRYGS gene.

Subjects and methods: A large six generation family affected by progressive polymorphic cortical cataract was investigated. After excluding loci for known cataract candidate genes using 39 fluorescent microsatellite markers, a whole genome scan was carried out.

Results: The disease was associated with inheritance of a $20.7 \mathrm{cM}$ locus on chromosome 3q26.3-qter, with a maximum LOD score of $6.34(\theta=0)$ at marker D3S1602. Haplotype analysis indicated that the disease gene lay at approximately $2.8 \mathrm{Mb}$ physical intervals between D3S1571 and D3S3570 and contained CRYGS on 3q27.3. By sequencing the CRYGS gene, a distinct 1619G $\rightarrow T$ (AC068631) heterozygous missense mutation in exon 2 was identified, co-segregating with the disease phenotype in this family and resulting in a glycine (GGC) to valine residue (GTC) substitution in codon 18 (NP_060011).

Conclusions: This report is the first description of a mutation in CRYGS with autosomal dominant cataract in humans.

C ataract characterised by opacities of the lens remains the leading cause of human blindness worldwide. Nonsyndromic congenital cataracts have an estimated frequency of 1-6 per 10000 live births, ${ }^{1}$ and one third of cases are familial. A strong genetic predisposition to the development of congenital cataract and age related cataract has been well documented. Recent work in molecular genetics has identified 14 genes involved in the pathogenesis of isolated inherited cataract, including seven coding for crystallins (CRYAA[MIM 123580], CRYAB[MIM123590], CRYBAl/A3[MIMI23610], CRYBBI[MIM600929], CRYBB2[MIM123620], CRYGC[MIMI23680], and CRYGD[MIM123690]), two for gap junctional channel protein (GJA3[MIM121015] and GJA8[MIM600897]), two for lens membrane protein (LIM2[MIM154045] and MIP[MIM154050]), one for beaded filament structural protein 2 (BFSP2[MIM603212]), one for glucosaminyl (N-acetyl) transferase 2 gene (GCNT2[MIM600429]), and one for heat shock transcription factor 4 (HSF4[MIM602438]). Twin studies on age related cataract in the United Kingdom estimate that two thirds of cortical cataracts and at least half the nuclear cataracts can be explained by genetic factors. ${ }^{2}{ }^{3}$ To investigate the molecular cause of cataract we studied a large Chinese family suffering from an autosomal dominant, progressive and polymorphic cortical cataract, and added another gene to growing list of genes involved in this heterogeneous monogenic disorder.

\section{METHODS}

We studied a Chinese six generation cataract family composed of 119 individuals with a dominant pattern of inheritance. Clinical information and blood specimens were obtained from 64 family members, including 14 patients. All participants had a full ocular assessment to document the phenotype. There was no evidence of other systemic and ocular defects.

After obtaining informed consent, we studied 11 loci for known candidate genes using three or four fluorescent microsatellite markers per locus, and no evidence of linkage was detected (data not shown). Subsequently a genome-wide scan consisting of 382 microsatellite markers spaced at $\sim 10 \mathrm{cM}$ intervals was carried out using ABI PRISM linkage mapping sets. This suggested a putative linkage on chromosome 3 (D3S1262 and D3S1601). We then undertook fine mapping (table 1). The order and position of the markers were obtained from the Marshfield Genetic Database (www.marshfield.org/genetics/maps). Genotyping and data collection were conducted by ABI Prism GeneMapper v.3.0 software. In the linkage analysis, we modelled the disease as an autosomal dominant inheritance with $90 \%$ penetrance, set the affected allele frequency at 0.00001 , and assumed the marker allele frequency to be uniformly distributed. We carried out two point linkage analysis using the MLINK program from the LINKAGE v.5.10 software package. Pedigree and haplotype construction were undertaken using Cyrillic v.2.1 software. We screened the mutation of candidate genes by bidirectional sequencing polymerase chain reaction products (300-600 bp).

\section{RESULTS}

The phenotype in this family was characterised by progressive opacities in the cortex with a ground glass appearance at an early age. The cataract is progressive and cataractous changes were prominent in affected older individuals, whose vision began to deteriorate between the ages of 8 and 15 years. Phenotypic variation in the size and density of the opacities and in their position was observed among the 14 affected members, who had no other inherited ocular or systemic abnormalities. The opacities could be located in the anterior, posterior, or peripheral cortex but no opacity was observed in the fetal nuclear region (fig 1). We identified a new autosomal dominant congenital cataract locus on chromosome 3q26.3-qter. Linkage analysis gave a maximum two point LOD score of $6.34(\theta=0.00)$ for marker D3S1602 (table 1).

Haplotype analysis (fig 2) indicated that the disease gene lay at approximately $2.8 \mathrm{Mb}$ physical intervals between D3S1571 and D3S3570. There are around 60 genes in this region including one crystallin gene CRYGS. The characteristic of the cataract in this family was the progressive appearance of opacities in secondary fibre cells, coinciding with the CRYGS expression pattern..$^{4-6}$ This gene therefore became an excellent candidate gene. The CRYGS gene spans 
Table 1 Two point LOD scores for linkage between the cataract locus and $3 \mathrm{q}$ markers

\begin{tabular}{|c|c|c|c|c|c|c|c|}
\hline \multirow[b]{2}{*}{ Marker order } & \multirow[b]{2}{*}{ Map location } & \multicolumn{6}{|c|}{ LOD scores AT $\theta=$} \\
\hline & & 0.0 & 0.1 & 0.2 & 0.3 & 0.4 & 0.5 \\
\hline D3S3725 & 181.87 & -5.48 & 2.76 & 2.26 & 1.55 & 0.72 & 0.00 \\
\hline D3S1556 & 183.47 & -11.46 & 0.20 & 0.77 & 0.76 & 0.45 & 0.00 \\
\hline D3S2425 & 185.4 & -10.93 & 1.43 & 1.50 & 1.11 & 0.53 & 0.00 \\
\hline D3S2421 & 186.68 & -5.88 & 1.50 & 1.46 & 1.09 & 0.57 & 0.00 \\
\hline D3S2427 & 188.29 & -12.62 & 0.28 & 0.65 & 0.57 & 0.29 & 0.00 \\
\hline D3S3715 & 190.43 & 0.64 & 0.52 & 0.39 & 0.23 & 0.07 & 0.00 \\
\hline D3S3699 & 191.79 & 0.86 & 0.74 & 0.64 & 0.50 & 0.29 & 0.00 \\
\hline D3S1571 & 193.75 & -0.63 & 3.49 & 2.90 & 2.06 & 1.02 & 0.00 \\
\hline D3S3583 & 195.6 & 1.53 & 1.30 & 1.06 & 0.78 & 0.43 & 0.00 \\
\hline D3S3570 & 201.14 & 2.59 & 2.13 & 1.64 & 1.11 & 0.56 & 0.00 \\
\hline D3S1262* & 201.14 & 3.78 & 3.11 & 2.36 & 1.55 & 0.74 & 0.00 \\
\hline D3S1602 & 201.14 & 6.34 & 5.27 & 4.09 & 2.76 & 1.29 & 0.00 \\
\hline D3S3600 & 203.81 & 3.82 & 3.14 & 2.39 & 1.55 & 0.68 & 0.00 \\
\hline D3S3530 & 209.41 & 2.01 & 1.69 & 1.33 & 0.91 & 0.42 & 0.00 \\
\hline D3S2398 & 209.41 & 5.19 & 4.30 & 3.31 & 2.20 & 0.99 & 0.00 \\
\hline D3S1314 & 212.61 & 5.16 & 4.28 & 3.29 & 2.19 & 0.99 & 0.00 \\
\hline D3S1601* & 214.45 & 3.43 & 3.73 & 3.09 & 2.21 & 1.12 & 0.00 \\
\hline D3S3663 & 214.45 & 3.24 & 2.60 & 1.89 & 1.11 & 0.34 & 0.00 \\
\hline D3S2418 & 215.84 & 1.09 & 1.07 & 0.90 & 0.63 & 0.30 & 0.00 \\
\hline D3S3669 & 215.84 & -4.71 & 3.41 & 2.86 & 2.02 & 0.99 & 0.00 \\
\hline D3S3562 & 217.24 & -5.11 & 1.32 & 1.28 & 1.02 & 0.59 & 0.00 \\
\hline D3S1265 & 222.83 & -10.46 & 2.39 & 2.15 & 1.56 & 0.81 & 0.00 \\
\hline D3S1311* & 224.88 & -1.13 & 1.34 & 1.08 & 0.66 & 0.25 & 0.00 \\
\hline
\end{tabular}

$6 \mathrm{~kb}$ and includes three exons. An alternative short transcript of the human CRYGS gene has been reported, with a disrupted open reading frame owing to the inclusion of part of intron $\mathrm{l}$ in the mature mRNA, producing a defective protein product with potentially deleterious results for the adult human lens. ${ }^{7}$ We therefore screened the mutation of the CRYGS gene in non-coding as well as in coding regions. By sequencing the CRYGS gene in two directions, we identified a 1619G $\rightarrow \mathrm{T}($ AC068631) heterozygous mutation in exon 2 of CRYGS, resulting in a Gly $\rightarrow$ Val substitution at codon 18 (NP_060011) in 14 affected members (fig 3). This mutation was not found in 50 unaffected members in this family, or in 342 chromosomes from 171 unrelated control individuals, excluding the possibility of a rare polymorphism.

\section{DISCUSSION}

Three major classes of crystallins $-\alpha, \beta$, and $\gamma$-are common to the eye lens throughout all vertebrates. The $\beta$ and $\gamma$ classes are made up of homologous proteins, and constitute the $\beta \gamma$ -

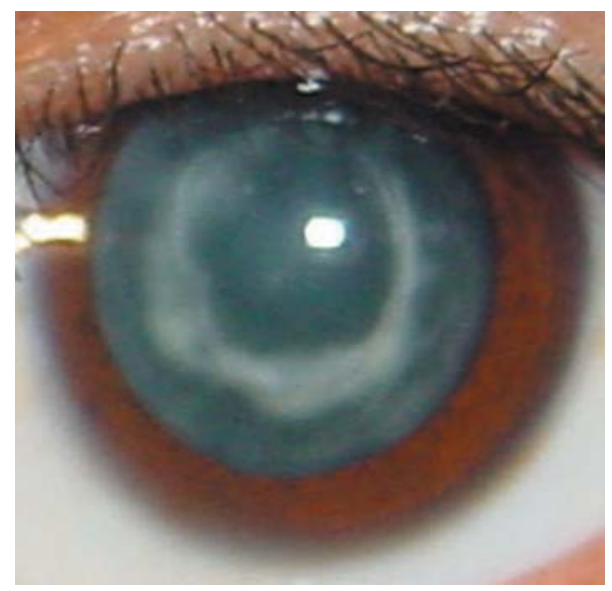

Figure 1 Eye photograph of individual IV:20, aged 35, from a six generation Chinese family, showing opacities located in the peripheral cortex of the lens. crystallin superfamily. CRYGS encodes $\gamma \mathrm{S}$-crystallin, a member of the $\beta \gamma$-crystallin superfamily. There are two groups of $\gamma$-crystallins. The best studied group consists of six genes $(\gamma \mathrm{A}$ to $\gamma \mathrm{F})$, which form a single cluster in primate and rodent genomes ${ }^{89}$ at human chromosome 2 or mouse chromosome 1 and affect early eye and lens development. Distinct from these is the $\gamma \mathrm{S}$-crystallin gene on human chromosome 3 or mouse chromosome 16, which is expressed late but abundantly in the ocular lens. The $\gamma S$ gene is also expressed outside the lens, particularly in the mature retina and cornea. ${ }^{10}$ It has been shown that the $\gamma$-crystallins are stress inducible in the retina ${ }^{11}$ and that the carotenoid- $\gamma \mathrm{S}-$ crystallin complex can protect the retina against photodamage. $^{12}$

$\gamma \mathrm{S}$-Crystallin, as a dominant structural component of the adult human lens, may play an important role in maintaining lens transparency. Formerly known as $\beta S$-crystallin, $\gamma \mathrm{S}$ crystallin was renamed when the structure of the bovine gene was determined and proved to be characteristic of the $\gamma$ rather than the $\beta$ family. ${ }^{5}$ In $\beta$-crystallins, each of four repeated structural motifs is encoded in a separate exon, while in $\gamma$-crystallins, the four motifs are coded as fused pairs in only two exons. $\gamma \mathrm{S}$-Crystallin has an additional $\alpha$ helix, which is located between the third and fourth $\beta$ sheets, ${ }^{13}$ and this is not found in the other $\gamma$-crystallins. $\gamma \mathrm{S}$-Crystallin resembles other $\gamma$-crystallins in gene structure and sequence, but is the most divergent member of the family. Findings based on structural and protein engineering studies or on molecular genetic analyses indicated that a series of gene alterations and fusions proceeded from crystallin ancestors coding for proteins made up of a single Greek key motif, which changed to two motif/one domain proteins, and then to two domain $\gamma$-type crystalline monomers, or to two domain/two monomer $\beta$ type dimmers. ${ }^{14}$ In many ways, $\gamma \mathrm{S}$ is a good candidate to represent the precursor of the $\gamma$ crystallins and possibly a link between the $\beta$ and $\gamma$ families. The $\gamma \mathrm{S}$-crystallin gene shows the expected high conservation, with $89 \%$ murine identity and $91 \%$ bovine identity (fig 4 ). Both the particularity of crystallins and the high degree of conservation across species suggest that CRYGS is essential for lens development. 


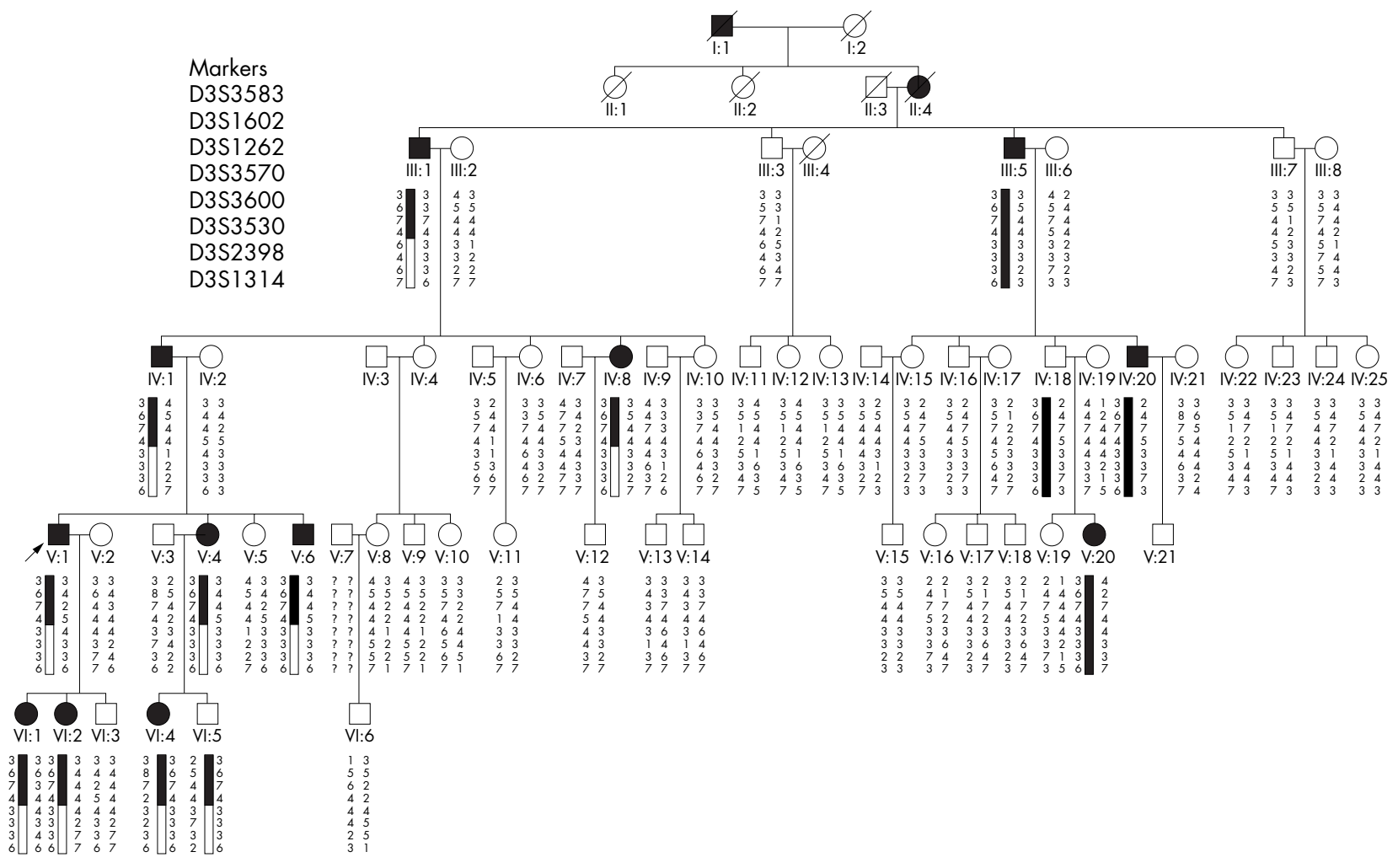

Figure 2 Pedigree and haplotype analysis of the six generation Chinese family. Haplotype analysis of 56 members in this Chinese family shows five microsatellite markers on chromosome 3 co-segregation in 14 patients. Squares and circles symbolise male and female individuals, respectively. Black symbols denote affected individuals. $\mathrm{V}: 1$ is the proband.

Classification of human inherited cataract is difficult because of the wide variation in morphologies observed. The phenotype in this family is rare, as opacities are restricted to a sector of cortical lens and the nucleus is unaffected, in contrast to lamellar cataract. This phenotype was similar to a Swiss family suffering from autosomal recessive cortical pulverulent cataract, which has been mapped to chromosome 9 q13-22, but the disease gene has not yet been cloned. ${ }^{15}$

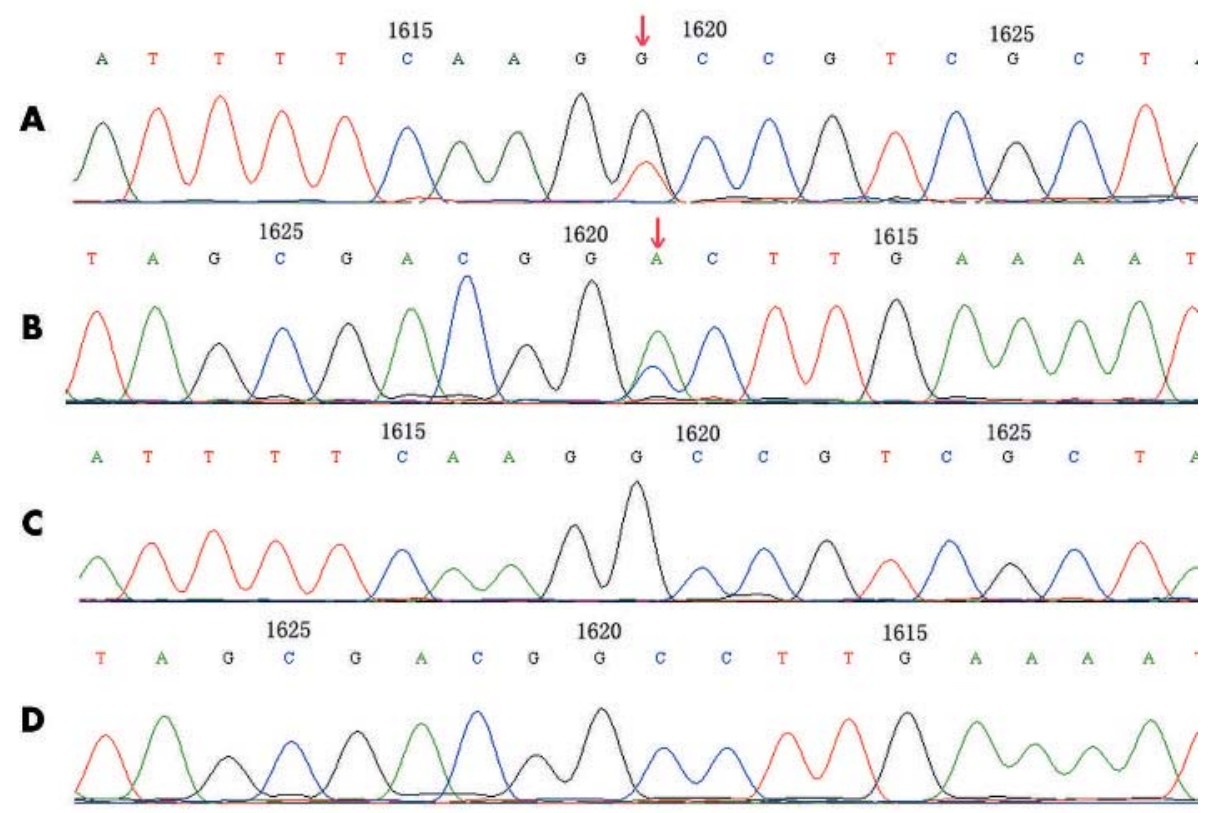

Figure 3 Mutational analysis of the $\gamma$ S-crystallin gene (CRYGS). A (sense chain) and B (antisense chain): sequence chromatograms showing a $1619 \mathrm{G} \rightarrow \mathrm{A}$ (AC068631) heterozygous transversion, which substitutes the amino acid glycine for valine (G18V) and was found in all affected individuals. C (sense chain) and D (antisense chain): the sequence change was not observed in any unaffected family members or in 171 unrelated control individuals. 


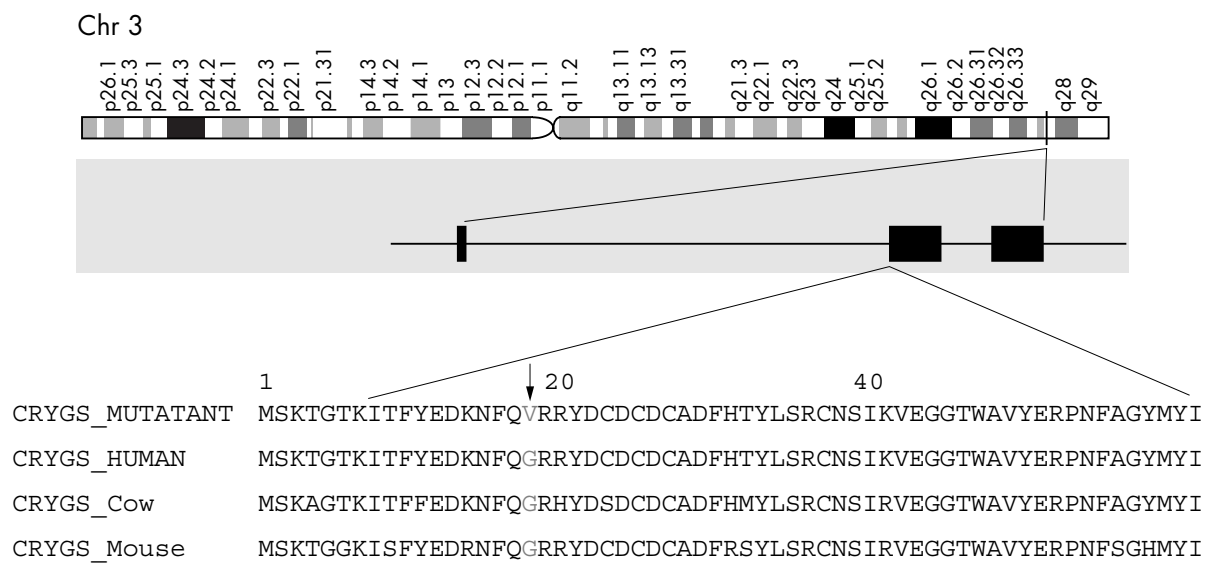

Figure 4 CRYGS mapping and multiple protein sequence alignment in different species. Reference sequence numbers of protein are human (NP_060011), cow (NP_776717), and mouse (NP_034097). The arrow directed the mutant amino acid residue.

Additionally, distributions of the opacities vary not only between family members but also between eyes in the same patient. This suggests that $\gamma \mathrm{S}$-crystallin may be involved in epithelial cell growth and migration, which in turn may contribute to lens fibre organisation. Our study indicates that a single base mutation, which results in a conservative sequence change of Gly $\rightarrow$ Val at residue 18 in $\gamma S$-crystallin, is associated with progressive cortical cataract. The mutant amino acid residue locates at the end of the first $\beta$ strand in the first "Greek key" motif. In vitro, $\gamma \mathrm{S}$-crystallin plays an important role in suppressing the aggregation of the $\gamma$ crystallins ${ }^{16}{ }^{16}$ There is evidence that early unfolding of $\beta$ - and $\gamma$-crystallins results in a substantial degree of secondary structural binding to $\alpha$-crystallin. ${ }^{17}$ In this way the unfolding protein can lead to opacification once the endogenous $\alpha$ crystallin is saturated. The $\mathrm{Gl} 18 \mathrm{~V}$ mutant protein may interfere with one or more of these functions, which disrupt the morphology and organisation of cortical fibre cells.

Additionally, it has been shown that the four stranded Greek key $\beta$ sheet peptide, corresponding to the crystallin fold, forms an individual calcium binding site and gives rise to the first calcium ligate at the residue next to the conserved aromatic amino acid in the sequence Y/E/WXXXXXXG, located at the end of the first $\beta$ strand. Glycine is necessary to form a dihedral angle, so it is irreplaceable. ${ }^{18}$ In the present family only this glycine mutated, probably leading to structural alterations in $\mathrm{Ca}^{2+}$ binding and storage ability. As calcium homeostasis in the lens may be disturbed and in turn trigger lens opacification, this could be a novel mechanism of cataract formation. Understanding the non-structural properties of the crystallins may be critical for an understanding of malfunction in the molecular cascades that lead to cataractogenesis, and its eventual therapeutic amelioration.

Finally, it is noteworthy that mutation of CRYGS has been found responsible for the murine Opj cataract, which is caused by a mutant protein that precipitates and aggregates in a temperature sensitive manner. ${ }^{10}$ The racat cataract, which is characterised by a spontaneous mutant transmitted as a recessive trait in the mouse, shares similar characteristics with the Opj cataract. ${ }^{19}$ These data strongly suggest a role for CRYGS in cataractogenesis.

\section{Conclusions}

Human $\gamma \mathrm{S}$-crystallin has to last a lifetime and thus requires both structural and kinetic stabilisation. In this study we have identified the first known mutation (G18V) of the CRYGS gene to be associated with autosomal dominant cataract in humans. This may help to further our understanding of the aetiology of cataract formation and of the function and properties of this gene. This study of a progressive phenotype and a CRYGS mutation may also provide insight into the cause of the more common sporadic form of age related cataract. The phenotype and location of the mutation suggest the need for further functional experiments to explore the critical nature of this residue in lens fibre organisation and long term stability.

\section{ELECTRONIC DATABASE INFORMATION}

Accession numbers and URLs for data in this article are as follows:

Center for Medical Genetics, Marshfield Medical Research Foundation, http://research.marshfieldclinic.org/genetics/ Online Mendelian Inheritance in Man (OMIM), http:// www.ncbi.nlm.nih.gov/Omim (CRYAA[MIM123580], CRYAB[MIM123590], CRYBAI/A3[MIMI23610], CRYBBI[MIM600929], CRYBB2[MIMI23620], CRYGC[MIM123680], CRYGD[MIMI23690], GJA3[MIMI21015], GJA8[MIM600897], LIM2[MIM154045], MIP[MIM154050], BFSP2[MIM603212], GCNT2[MIM600429], HSF4[MIM602438]).

Clustal W, http://clustalw.genome.ad.jp/

\section{ACKNOWLEDGEMENTS}

We thank the patients who contributed samples for analysis in this study. We are grateful to all of the individuals described here for their contribution to this study. This research was supported by the National High Technology "863" Programmes of China (grant No 200BA711A07).

\section{Authors' affiliations}

H Sun, Z Ma*, Z Li, W Ma, X Tang, X Li, Eye Centre of Tianjin Medical University, Tianjin, China

B Liu, National Centre of Human Genome Research (Beijing), Beijing, China

Y Li, X Ding, Y Gao, Zhoukou Eye Hospital, Henan, China

Y Shen, National Laboratory of Medical Molecular Biology, Institute of Basic Medical Sciences, Chinese Academy of Medical Sciences/Peking Union Medical College, Beijing, China

*Huimin Sun and Zhiwei Ma contributed equally to this work Competing interests: none declared

Correspondence to: Professor Yan Shen, National Centre of Human Genome Research (Beijing), North Yongchang Road BDA, Beijing 100176, China; sheny@ms.imicams.ac.cn

Received in revised form 15 December 2004

Accepted for publication 16 December 2004 


\section{REFERENCES}

1 Lambert SL, Drack AV. Infantile cataracts. Surv Ophthalmol 1996;40:427-58

2 Hammond CJ, Snieder H, Spector TD, Gilbert CE. Genetic and environmental factors in age-related nuclear cataracts in monozygotic and dizygotic twins. N Engl J Med 2000;342:1786-90

3 Hammond CJ, Duncan DD, Snieder H, de Lange M, West SK, Spector TD Gilbert CE. The heritability of age-related cortical cataract: the Twin Eye Study. Invest Ophthalmol Vis Sci 2001;42:601-5.

4 Lubsen NH, Arts HJ, Schoenmakers JG. The evolution of lenticular proteins: the beta- and gamma-crystallin super gene family. Prog Biophys Mol Biol 1988; $51: 47-76$

5 van Rens GL, Raats JM, Driessen HP, Oldenburg M, Wijnen JT, Khan PM, de Jong WW, Bloemendal $\mathrm{H}$. Structure of the bovine eye lens gamma s-crystallin gene (formerly beta s). Gene 1989;78:225-33.

6 Jaworski C, Wistow G. LP2, a differentiation-associated lipid-binding protein expressed in bovine lens. Biochem J 1996;320:49-54.

7 Wistow G, Sardarian L, Gan W, Wyatt MK. The human gene for gammaScrystallin: alternative transcripts and expressed sequences from the first intron. Mol Vis 2000;6:79-84.

8 Lubsen NH, Aarts HJ, Schoenmakers JG. The evolution of lenticular proteins: the beta- and gamma-crystallin super gene family. Prog Biophys Mol Biol 1988:51:47-76.

9 van Rens GL, de Jong WW, Bloemendal HA. Superfamily in the mammalian eye lens: the beta/gamma-crystallins. Mol Biol Rep 1992;16:1-10.

10 Sinha D, Wyatt MK, Sarra R, Jaworski C, Slingsby C, Thaung C, Pannell L, Robison WG, Favor J, Lyon $M$, Wistow $G$. A temperature-sensitive mutation of Crygs in the murine Opj cataract. J Biol Chem 2001;276:9308-15.
11 Jones SE, Jomary C, Grist J, Makwana J, Neal MJ. Retinal expression of gamma-crystallins in the mouse. Invest Ophthalmol Vis Sci 1999;40:3017-20

12 Roll B. Carotenoid and retinoid-two pigments in a gecko eye lens. Comp Biochem Physiol A Mol Integr Physiol 2000;125:105-12.

13 Bagby S, Harvey TS, Kay LE, Eagle SG, Inouye S, Ikura M. Unusual helixcontaining greek keys in development-specific $\mathrm{Ca}^{2+}$-binding protein $\mathrm{S}$. ${ }^{1} \mathrm{H}$, ${ }^{15} \mathrm{~N}$, and ${ }^{3} \mathrm{C}$ assignments and secondary structure determined with the use of multidimensional double and triple resonance heteronuclear NMR spectroscopy. Biochemistry 1994;33:2409-21.

14 Giuseppe DA. The evolution of monomeric and oligomeric $\beta \gamma$-type crystallins. Eur J Biochem 2002;269:3122-30.

15 Heon E, Paterson AD, Fraser M, Billingsley G, Priston M, Balmer A, Schorderet DF, Verner A, Hudson TJ, Munier FL. A progressive autosomal recessive cataract locus maps to chromosome 9q13-q22. Am J Hum Genet $2001 ; 68: 772-7$.

16 Liu C, Pande J, Lomakin A, Ogun O, Benedek GB. Aggregation in aqueous solutions of bovine lens $\gamma$-crystallins: special role of gamma(s). Invest Ophthalmol Vis Sci 1998:39:1609-19.

17 Das KP, Choo-Smith LP, Petrash JM, Surewicz WK. Insight into the secondary structure of non-native proteins bound to a molecular chaperone alphacrystallin. J Biol Chem 1999;274:33209-12.

18 Rajini B, Shridas P, Sundari CS, Muralidhar D, Chandani S, Thomas F Sharma Y. Calcium binding properties of gamma-crystallin: calcium ion binds at the Greek key beta gamma-crystallin fold. J Biol Chem $2001 ; 276: 38464-71$

19 Bu L, Yan S, Jin M, Jin Y, Yu C, Xiao S, Xie Q, Hu L, Xie Y, Solitang Y, Liu J, Zhao $G$, Kong $X$. The $\gamma$ S-crystallin gene is mutated in autosomal recessive cataract in mouse. Genomics 2002;80:38-44.

\section{bmjupdates+}

bmjupdates+ is a unique and free alerting service, designed to keep you up to date with the medical literature that is truly important to your practice.

bmjupdates+ will alert you to important new research and will provide you with the best new evidence concerning important advances in health care, tailored to your medical interests and time demands.

Where does the information come from?

bmjupdates+applies an expert critical appraisal filter to over 100 top medical journals A panel of over 2000 physicians find the few 'must read' studies for each area of clinical interest

Sign up to receive your tailored email alerts, searching access and more...

www.bmjupdates.com 